\section{The Saturday Evening Post and public relations}

During the recent AOA convention in Las Vegas, D.O.s were very pleased with the November 1986 issue of the Saturday Evening Post. On the inside back cover and facing page, a pictorial advertisement explained the meaning of the D.O. degree and promoted the D.O. as the "family physician, an idea whose time has come-again."

This great public relations piece was cosponsored by the Missouri Association of Osteopathic Physicians and Surgeons and its Auxiliary. But this cooperative endeavor did not stop there. The original advertisement had been developed under the auspices of Normandy Osteopathic Hospital, with some seed money from the Missouri Auxiliary and the aid of several people both within and outside the profession. Not to be overlooked was the cooperation of the editor and the president of the Saturday Evening Post Society. Perhaps more than with any other public relations effort in the past decade, the result emphasizes the importance of a variety of sources coming together in a common purpose.

It is true that public relations begins as a solo effort in the physician's office, for he or she is often the only representative of the profession with whom many people come in contact. However, ads, television spots, talk shows, and the like are more often achieved through a joint effort. Together, people can make it happen.

GEORGE W. NORTHUP, D.O., FAAO

\section{Somatic dysfunction and myocardial infarction}

Investigation into the mechanisms which support the clinical observation that visceral disorders may be reflexly manifested as somatic dysfunction continues in many of our osteopathic medical colleges. Featured in the Original Contributions section of this issue are yet two more controlled clinical studies contributing to the scientific basis of this principle of osteopathic medicine.
In "A somatic component to myocardial infarction," reprinted from the British Medical Journal, Nicholas, DeBias, and associates report that myocardial infarction is accompanied by characteristic paravertebral soft-tissue changes, which are readily detected by palpation. The blinded study revealed a significantly higher incidence of softtissue changes in the study group of patients with confirmed acute myocardial infarction, as well as in an excluded group of patients with heart disease other than myocardial infarction, than in the control group of subjects without known cardiovascular disease. The site of somatic dysfunction was located almost exclusively in the area T1 to T4.

In "Correlation of palpatory observations with the anatomic locus of acute myocardial infarction," Rosero, Greene, and DeBias examine the link between the description of the somatic component of a myocardial infarction and its location. Their results suggest that somatic dysfunction is more apparent in myocardial infarction of the anterior wall and is less well defined in infarction of the other walls.

These investigations and others to come will aid in understanding the physiologic mechanisms involved in the complex somatovisceral interrelationship.

THOMAS W. ALLEN, D.O., FACOI

\section{The bottom line-again}

Although the average hospital stay in the U.S. fell from 6.6 days in 1984 to 6.4 days in 1985, the average cost per stay rose 7.5 percent. Hospital visits ranged from the longest stay of 8.5 days in Washington, D.C., to the shortest admission of 4.1 days in Alaska. And while the average stay cost was $\$ 2,180$ in South Dakota, the average bill in California would be $\$ 5,107$. These findings, the result of an annual survey of 2,362 hospitals conducted by the Hospital Association of America and the Equitable Group and Health Insurance Company, were published in the December 3,1986, issue of USA Today.

Of course, any set of figures can be made to ap- 
pear significant or trifling, depending upon the reader's mind set. But these particular statistics do recall a point made several times on these pagesthat it is not the length of stay that is necessarily responsible for rising health care costs. In our opinion, the high cost of inpatient admission relates directly to the number of diagnostic and therapeutic procedures performed purely on the basis of fear. If something goes wrong, will the question "You mean that you didn't even order a CAT scan?" be posed in the courtroom?

Health care costs will never be controlled until the practice of defensive medicine is reduced. As long as professional liability claims continue to escalate, million-dollar settlements persist, and sky-high insurance rates soar ever upward, the cost of hospital care also will continue to rise.

To the best of our knowledge, there has never been a study to assess the cost of defensive medicine. We need to gain an approximate calculation of this burden on the health care system. The price would, no doubt, be surprisingly high. Until the bottom line of this expense is considered and relieved, the high cost of inpatient medical care will continue unabated.

GEORGE W. NORTHUP, D.O., FAAO

\section{In my opinion}

From time to time, we have received articles which express personal opinions on many topics. They are often too long to publish as a "Letter to the Editor" and too short to publish as an article. In response to this editorial quandary, THE Do has launched a new section for these commentaries-aptly called "In My Opinion." Without exception, the articles will be subjected to the usual editing process and their acceptance or rejection will be the sole responsibility of the editors. The articles will bear the name of the author and represent his or her reflective opinion on matters of interest and concern to the profession.

"In my opinion" will not necessarily be a monthly feature. However, if the amount of material received in the past is any indication, we believe that the column will appear frequently.

The first article to be published in this new section of THE DO is written by AOA trustee and chairman of the AOA Editorial Policy Committee, William G. Anderson, D.O., who shares his ideas on quality assurance in the osteopathic profession. His comments were originally presented at the national seminar of the American College of Utiliza- tion Review Physicians last October. They will appear in March.

Dr. Anderson and others whose opinions will be published on these pages do not seek or expect universal agreement with all matters proposed. But they do invite feedback, constructive criticisms, and the opinions of others in our professional family.

GEORGE W. NORTHUP, D.O., FAAO

\section{editorial comment}

Intravenous feedings of vitamins $A$ and $E$ may help to prevent retinopathy and bronchopulmonary dysplasia in premature babies, according to Harry L. Greene, M.D., professor of pediatrics at Vanderbilt University School of Medicine in Nashville.

Dr. Greene, who presented his findings at the Bristol-Myers Symposium on Nutrition Research, has two difficulties to overcome with this therapy. First, vitamin A appears to be destroyed by light, and neonate nurseries are always well lighted. Second, because the vitamin A mixture tends to stick to the plastic intravenous tubing, only 10 to 15 percent of the vitamin actually reaches the babies. The researcher is working on a lipid preparation that would correct both problems.

All exercise programs are not created equal, at least as far as spinal bone mineral density is concerned. Researchers at the University of California-San Francisco used computed tomography to measure spinal bone density in 28 men who pursued various exercise programs and in 18 sedentary individuals.

Results showed that men who combined weight training with aerobic exercise had the greatest spinal bone density. Those who used only free weights or "resistance" equipment ranked second, followed by those with only an aerobics program, such as jogging or "jazzercise." Nonexercisers had the lowest spinal bone density.

Monosodium glutamate (MSG) may be getting a bum rap as the culprit of the so-called "Chinese restaurant syndrome." For more than a decade, the flavor enhancer has been blamed for a burning, tightness, or numbness around the face, neck, or chest in patrons who eat Chinese cuisine or other foods that contain the seasoning.

A researcher at George Washington University 